\title{
Seismic performance assessment of steel bracing systems in high-rise reinforced concrete structures
}

\author{
Peter Kirruti $^{1}$ iD , Ayse Pekrioglu Balkis ${ }^{* 2}$ iD \\ ${ }^{1}$ Cyprus International University, Institute of Graduate Studies, Nicosia, Turkish Republic of North \\ Cyprus, Mersin 10, Turkey \\ ${ }^{2}$ Cyprus International University, Department of Civil Engineering, Nicosia,Turkish Republic of North \\ Cyprus, Mersin 10, Turkey
}

\begin{abstract}
The seismic performance of Concentric Steel Bracing systems in modelled reinforced concrete (RC) frames is investigated. High-rise RC frames were designed and analysed based on Eurocode (EC) guidelines on Reinforced Concrete (EC2), Steel design (EC3) and Seismic design (EC8). Examination was performed in 3 stages: modelling and analysing a 20 story moment resisting frame, followed by 3 uniformly braced frames (both internally and externally) and finally a combined brace frame - whose bracing system was selected from the two best performing uniform systems. Parameters assessed were: story drifts and accelerations, joint displacements and accelerations, base reactions and story stiffness employing Modal Response Analysis. Results obtained pointed to several key achievements. Firstly, that capacity design was possible within set guidelines for high-rise structures. Based on the analysis parameters, absorption and dissipation of lateral forces was observed with increases in joint displacements and accelerations in the $\mathrm{Z}$ direction (perpendicular to ground motion). Correlative relationships linking story stiffness with story drift, and Story Stiffness with Joint Displacements and Accelerations were derived from data resulting from the analysis. Combining bracing systems produced marginal performance improvements compared to uniform concentric systems, and base reaction results showed that there was low improvement base shear and moments with the incorporation of braces.
\end{abstract}

\section{Keywords}

Modal response spectrum analysis; High-rise reinforced concrete; Steel bracing systems; 3D structural modelling.

Received: 08 October 2019; Accepted: 19 March 2020

ISSN: 2630-5763 (online) C 2020 Golden Light Publishing All rights reserved.

\section{Introduction}

A simple description of Bracing Systems would be that they are strengthening systems used in structural frames to aid in their resistance to lateral loads. Their function is to increase the lateral stiffness and distribute lateral forces throughout

\footnotetext{
* Corresponding author

Email: apekrioglu@ciu.edu.tr
}

structural frame in order to improve its resistance and performance under seismic loads [1].

The possible integration of steel braces was researched into as far back as the late 1970s to early 1990s. Initial approaches were described as an "indirect" method where either steel braces were encased in concrete or using box framed braces to 
strengthen RC frames [2]. These approaches took the form of laboratory experimentation with use of RC models of varying configurations: from single square frames with braces incorporated into them to scaled multi-story frames. In order to determine the force carrying/dissipation performance evaluated by measuring buckling performance, structural deflections and displacement, failure mechanisms under load and member deformations by subjecting the test structure to either static to cyclic lateral loads, Positive conclusions such as improvements in RC member shear performance under load, increased structural stiffness and overall performance increase under seismic loads were drawn $[3,4]$. Criticisms of this approach were that they would be expensive and difficult to employ as a means of retrofitting existing structures and means of connection were not highly effective in lateral force translation when applied in structures [2].

A "direct" method was subsequently proposed and its utilization involved connecting the steel brace elements to RC members by means of plates and bolts. Ensuing research followed the direct approach of application and assessment of these systems. The advent of complex structural modelling software and improvements in laboratory testing paved the way to allow various researchers to explore multiple aspects of application of bracing systems. Work by Badoux and Jirsa in 1990 explored the use of these systems as a possible retrofitting method for structurally inadequate structures by designing and modelling braced RC frames and testing drift control and collapse prevention among other parameters [5]. They observed significant improvements in frame stiffness and reductions in drift and deformations. Research by Maheri and Akbari [6] explored the effect of on ductility by behaviour factor (R or q) in modelling braced RC Structures. Youssef, Ghaffarzadeh and Nehdi [7] tested bracing systems by designing and constructing scaled moment resisting frames with bracing elements and observed improvements in ductility and that capacity design limits set out in design codes were achievable. Godínez-Domínguez et al [8] alongside other researchers explored areas such as non-linear behaviour of code designed RC frames, software modelling of RC frames in 2D and 3D, mechanical testing of scaled models and connection types, potential retrofitting options and dissipative performance of bracing systems for pre-existing structures. Additionally, they also investigated were the global performance of these systems on multi-story RC frames, localized performance (force-load transmission and member performance), suitability of types of braces, and whether existing design codes can be used to design and analyse bracing systems.

Some advantages have been noted by various researchers. Considerable increase of the lateral resistance of a frame highlighted by Zhe et al [9] in their work on zig-zag configuration of diagonal braces without buckling restraints. They stated that lateral stiffness can be increased considerably with the use of braces. Increase in the level of strength and stiffness can enhanced relatively easily by the choice of the number, size and configuration of the braces [10]. The ductility and hysteretic behaviour can be obtained easily through proper design [11]. New systems can be designed to carry the entire lateral loads, which is particularly advantageous if the frame is of an unfavourable failure mechanism. There is also suggested adequate control over the flow of force (load path to effectively transfer forces from the elements to the foundations) and minimum local force concentration; there is minimal added weight to the structure in comparison to other traditional strengthening systems [2].

However, some notable disadvantages are: There exists difficulty in the control of the interaction between new steel and existing concrete systems [12], these systems are not efficient for stiff concrete structures, there is a degree of sensitivity in the detailing of braces and connections against local buckling and post-buckling fracture. Additionally, formation of proper connections between concrete and steel frames may be difficult due to factors such as the permeability of the concrete, the grouting materials' adhesion to the joining members, etc. [13]. 
Although substantial research has been done covering these systems, there are several areas of inquiry that are relatively new. Areas such as the effect of these systems on distribution of lateral accelerations on tall multi-storey structures, employing the use Modal Response Spectrum analysis as a means of assessment and a comparative analysis of these systems on structural frames following code design guidelines.

\section{Assessment parameters}

Performance evaluation for the modelled frames was based on the following parameters:

- Story Drifts - by definition, it is the lateral displacement between one story and that below it. In this case, reductions in drift would be assessed and compared between the systems. Work by Valente [11] and Muralidhar et al [14] showed improvements in drift performance of Mid-rise structures with the incorporation of braces in their frames and this would be a suitable measure for high-rise structures

- Story Accelerations - lateral accelerations experienced at each story of all the frames are assessed in order to see what effect the bracing systems have of the RC frame in transmission and dissipation of seismic forces. One aspect of using bracing systems that been identified from research is the ability of these systems to transfer and distribute lateral forces from the base of the frame to other structural elements throughout the structure.

- Joint displacements and accelerations - in assessing the behaviour of these systems, one area that has little research on is the effect of these systems on joints for high-rise structures. Therefore, reductions and accelerations are to be assessed and performance compared.

- Base Reactions - Work Vijayakumar et al [15] shwed that base reactions in multi-story braced frames were effective indicators of the capacity of these systems to transfer lateral load from the frame to the base.

- Structural stiffness - in 2010, work by GodínezDomínguez et al [1] showed bracing systems do provide considerable lateral strength increases to RC frames. Therefore, a comparison of the improvement in lateral strength of these systems was made and its effect assessed by the aforementioned parameters.

\section{Structural modelling}

\subsection{Model descriptions}

Each model had a plan area that measured $68 \times 58 \mathrm{~m}$ with a total of 11 bays. The total height was $71.3 \mathrm{~m}$, with the tallest story measuring $4.2 \mathrm{~m}$ and shortest $3.5 \mathrm{~m}$. The reason for the large area for the frame is was to be considered as a multi-purpose commercial building.

Frame elements were designed according to guidelines set out in EC2 (Reinforced Concrete Design) and EC3 (Steel Design). Large concrete frame sections $(\mathrm{C} 110 \times 110, \mathrm{C} 100 \times 100, \mathrm{BM} 60 \times 80)$ were used on interior sections of lower stories of the structure from 1 st to 4 th, and smaller concrete sections were used on the rest of the frame. Table 1 gives a summary of properties of the frame sections.

Table 1. Frame sections details

\begin{tabular}{|c|c|c|c|c|c|c|}
\hline Name & $\begin{array}{c}\text { Material } \\
\text { class }\end{array}$ & $\begin{array}{c}\text { Dimensions } \\
(\mathrm{mm})\end{array}$ & $\begin{array}{c}\text { Modulus of } \\
\text { elasticity E (MPa) }\end{array}$ & $\begin{array}{l}\text { Poisons } \\
\text { ratio } v\end{array}$ & $\begin{array}{c}\text { Unit weight } \\
\left(\mathrm{kN} / \mathrm{m}^{3}\right)\end{array}$ & Design strengths \\
\hline BM60×70 & $\mathrm{C} 30 / 37$ & $600 \times 700$ & 33000 & 0.2 & 24.992 & $\mathrm{~F}_{\mathrm{c}}=30 \mathrm{MPa}$ \\
\hline BM60×70' & $\mathrm{C} 40 / 50$ & $600 \times 700$ & 35000 & 0.2 & 24.993 & $\mathrm{~F}_{\mathrm{c}}=40 \mathrm{MPa}$ \\
\hline $\mathrm{BM} 60 \times 80$ & $\mathrm{C} 40 / 50$ & $60 \times 800$ & 35000 & 0.2 & 24.993 & $\mathrm{~F}_{\mathrm{c}}=40 \mathrm{MPa}$ \\
\hline $\mathrm{C} 100 \times 100$ & C50/60 & $1000 \times 100$ & 37000 & 0.2 & 24.993 & $\mathrm{~F}_{\mathrm{c}}=50 \mathrm{MPa}$ \\
\hline $\mathrm{C} 110 \times 110$ & C50/60 & $1100 \times 1100$ & 37000 & 0.2 & 24.993 & $\mathrm{~F}_{\mathrm{c}}=50 \mathrm{MPa}$ \\
\hline $\mathrm{C} 80 \times 80$ & $\mathrm{C} 40 / 50$ & $800 \times 800$ & 35000 & 0.2 & 24.993 & $\mathrm{~F}_{\mathrm{c}}=40 \mathrm{MPa}$ \\
\hline $\mathrm{C} 90 \times 90$ & $\mathrm{C} 40 / 50$ & $900 \times 900$ & 35000 & 0.2 & 24.993 & $\mathrm{~F}_{\mathrm{c}}=40 \mathrm{MPa}$ \\
\hline $\mathrm{C} 95 \times 95$ & $\mathrm{C} 40 / 50$ & $950 \times 950$ & 35000 & 0.2 & 24.993 & $\mathrm{~F}_{\mathrm{c}}=40 \mathrm{MPa}$ \\
\hline $\mathrm{C} 95 \times 95^{\prime}$ & $\mathrm{C} 50 / 60$ & $950 \times 950$ & 37000 & 0.2 & 24.993 & $\mathrm{~F}_{\mathrm{c}}=50 \mathrm{MPa}$ \\
\hline Bracing Section & $\mathrm{S} 450$ & $200 \times 200 \times 15$ & 210000 & 0.3 & 76.973 & $\begin{array}{l}F_{y}=440 \mathrm{MPa} \\
F_{u}=550 \mathrm{MPa}\end{array}$ \\
\hline
\end{tabular}


The bracing elements were Steel I/Wide Flanges and were used on selected interior and exterior frame sections, as seen in elevations of section $\mathrm{A}$ and $\mathrm{E}$ (Fig. 1). Exterior braces were places on elevations A, L, 1 and 12, while interior braces were placed on elevations E, H, 5 and 8 .

\subsection{Design loads and parameters}

In accordance to EC8, certain design factors were considered. The behaviour factor (q) for ductility and overstrength was set to 4.5 (Mid to High ductility class EC2 and EC8). The design ground motion was set to $0.4 \mathrm{~g}$ (Default maximum PGA EC8-CEN 2004 for ground type B are shown in Fig. 2) and dampening factor (Eccentricity factor) for the frame and its elements set to $5 \%$. This given data was used to create the Response Spectrum Function that was used in applying a MRSA with ETABs software. For the wind loads, wind velocity was set to a maximum of $27 \mathrm{~m} / \mathrm{s}$ and was to act on all eternal frame elements [16]. The gravity loads are given in Table 2 .
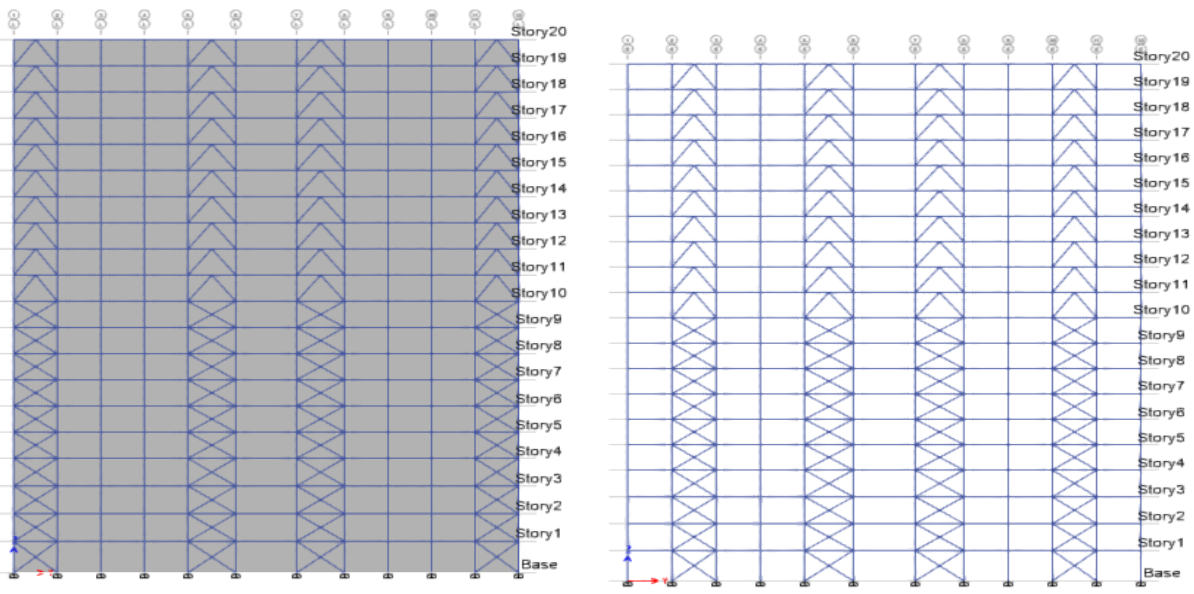

Fig. 1. Elevation A (top left) - Exterior section and elevation E (top right) - Interior section

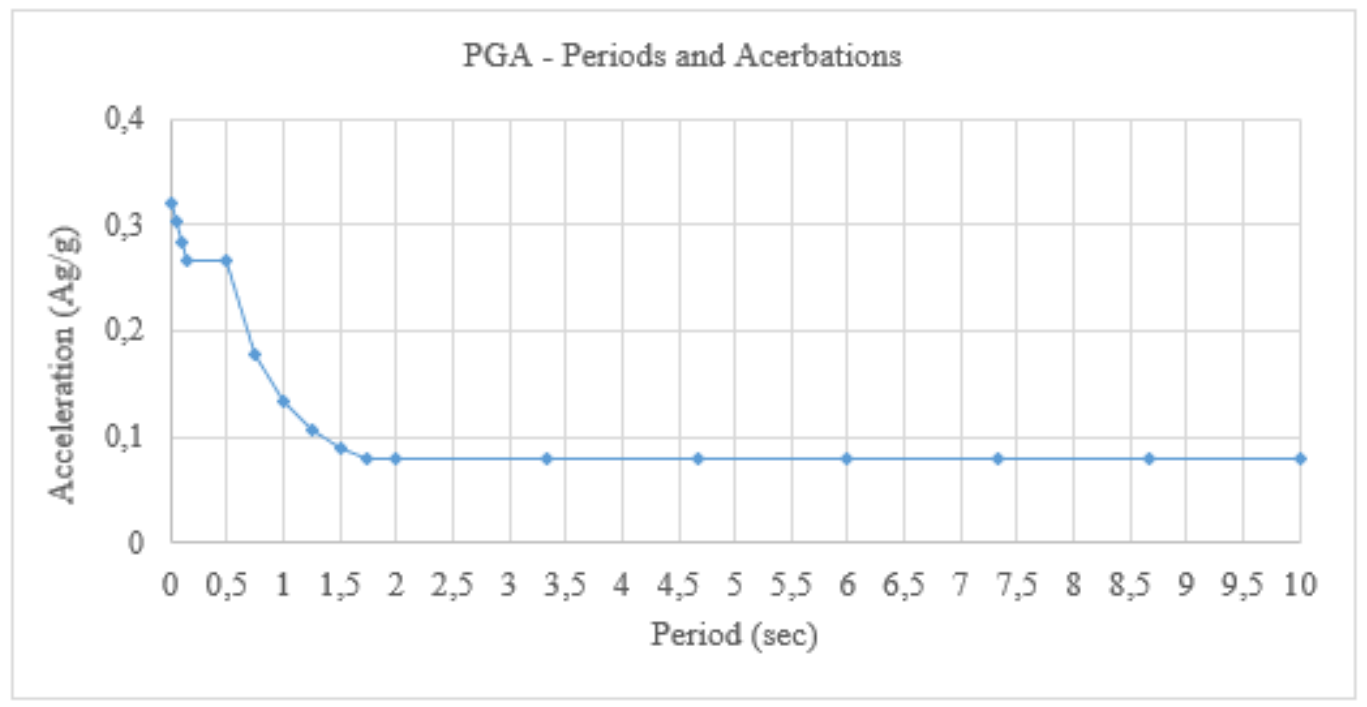

Fig. 2. EC8 Response spectrum function graph for ground type B 
Table 2. Applied design loads

\begin{tabular}{llcc}
\hline Load & Type & Magnitude $\left(\mathrm{kN} / \mathrm{m}^{2}\right)$ & Applied section \\
\hline Dead & Distributed & 1.25 & Slabs - 5-20th stories \\
Dead & Distributed & 2 & Slabs - 1-4th stories \\
Live & Distributed & 4.8 & Slabs - 5-20th stories \\
Live & Distributed & 6.5 & Slabs - 1-4th stories \\
Dead (Surcharge) & Distributed & 2.25 & Slabs - 5-20th stories \\
Dead (Surcharge) & Distributed & 3.2 & Slabs - 1-4th stories \\
Partition & Distributed & 9.75 & All Interior beams \\
Curtain walls (Cladding) & Distributed & 3.25 & All Exterior Beams \\
\hline
\end{tabular}

\subsection{Modal Response Spectrum Analysis (MRSA)}

In Modal Response Spectrum Analysis, modal shapes (eigenvectors) are setup in 3-dimensions, and the natural frequencies (eigenvalues) are computed. Once these values are obtained, each modal shape, that is represented by a vector $\Phi_{\mathrm{n}}$ for each computed mode (n), will in general have displacements and rotations in all three directions, $\mathrm{X}, \mathrm{Y}$ and $\mathrm{Z}$ for all nodes $\mathrm{i}$ (the number of modes computed) of the structural model. Each eigenvalue is computed for all DOFs (Degree of freedoms) that are set at each member connection of the structure. [16]

In modelling, all frame members were assumed to have $3 \mathrm{DoFs}$ to be analysed and due to this, the number of Eigen modes was set for analysis was 100. The reason for this was because the structural models had a large number of nodes (over 3100) for analysis. Modal participation mass for MRSA, according EC8, is set to at least $90 \%$ of the total mass of the frame. This Mass participation factor (MPF) is considered for all planar directions (X, Y and $\mathrm{Z}$ ) and from analysis, the percentages are considered as sums in the given direction. From the MRSA, all structures fulfilled this requirement at the 100th eigenmode with the lowest percentage being that of the Combined $\mathrm{X}$ and Inverted $\mathrm{V}$ braced frame $(98.59 \%$ in the $\mathrm{Y}$ direction). The design peak ground motion was set to $0.4 \mathrm{~g}$ and its function and periods are given in Fig. 2.

The modelling of the frames was made in three stages using ETABS design software: First, a baseline non-braced moment resisting frame was designed and analysed according to EC2 guidelines. Loads tested were only gravity and wind loads and capacity checks were done on all frames. In the second stage, concentric braces $(\mathrm{X}, \mathrm{V}$ and Inverted $\mathrm{V}$ ) were applied on interior and exterior sections of the frames, resulting in three braced structural frames. All models were subsequently put through MRSA and their seismic performance assessed according to story drifts and accelerations, joint displacements and accelerations, base reactions and frame stiffness results.

In the third stage, a combined brace structure was then modelled based on the performance of the uniformly braced structures and its results compared with all other frames. Results from the analysis of the uniform systems showed that the best combination of systems was $\mathrm{X}$ for lower stories, i.e., 1st to 10th, and Inverted V for upper stories, i.e., 11th to 20th. The results from the modelling were then be used to make comparisons of the performance of all the models.

\section{Results and observations}

\subsection{Inter-story drift}

From the analysis, it was observed that there were reductions in story drift in both lateral directions ( $\mathrm{X}$ and Y). From results presented in Figs. 3 and 4 all the braced frames showed a reduction in lateral drift for all stories apart from the top story (20th). Drift in $\mathrm{X}$ direction increased to $18 \%$ (X braced), $13 \%$ (Inverted V), 9.8\% (V braced) and $11.5 \%$ (Combined System), while $\mathrm{Y}$ direction increase was $18.2 \%$ (X braced), $11.8 \%$ (Inverted V), 15.8\% (V braced) and 13.6\% (Combined System). 


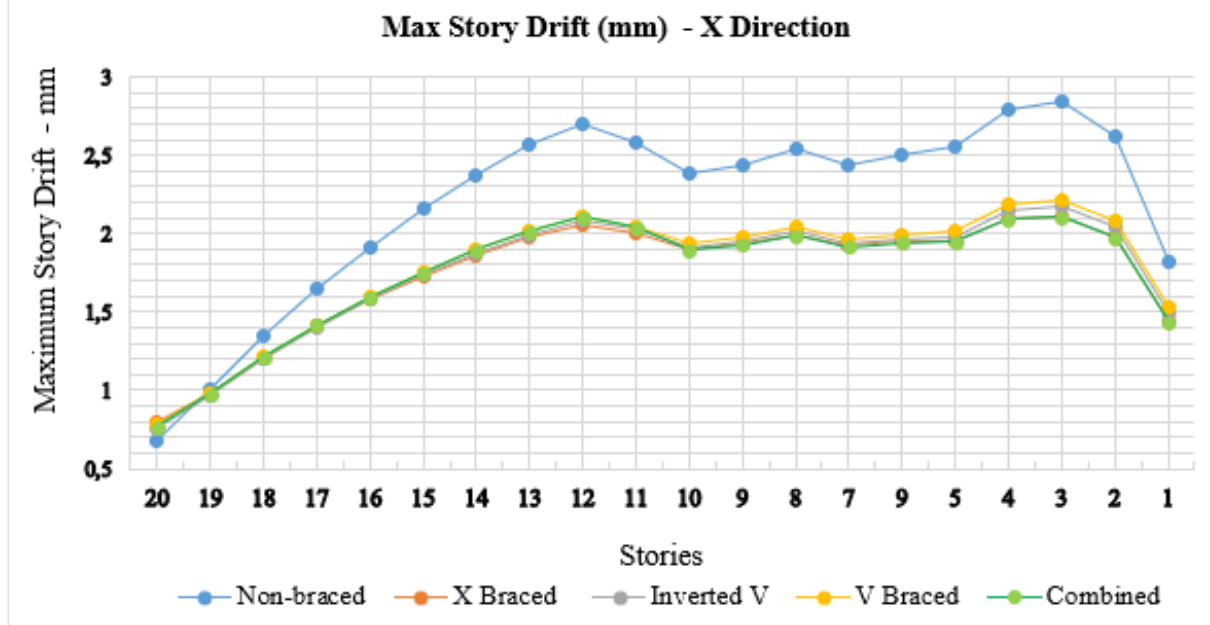

Fig. 3. Maximum story drift (mm) $\mathrm{X}$ direction

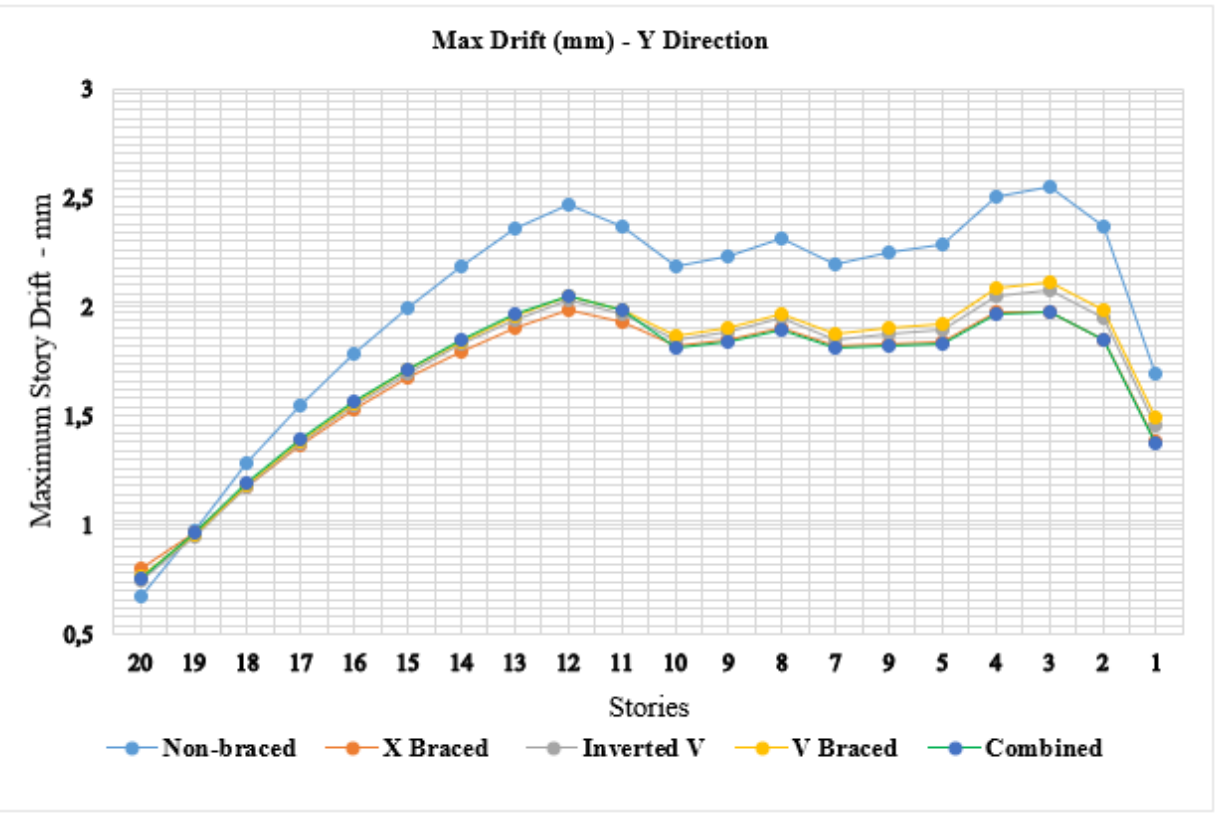

Fig. 4. Maximum story drift (mm) Y direction

Drift reductions occurred between the 19th and 1 st stories, following a descending pattern for the braced frames. In both $\mathrm{X}$ and $\mathrm{Y}$ directions, the $\mathrm{X}$ braced frame had the best overall performance, with a general drift reduction of $8.1-29.4 \%$, followed by the inverted $\mathrm{V}-8.03$ to $28.7 \%$, while the $\mathrm{V}$ braced frame was $7.9-28.6 \%$. The combined frame had a range of 8.02 to $28.8 \%$. The largest reductions in drift occurred the 15th to the 1st, where the reduction was above $21 \%$ for all the braced frames.

When comparing the systems, the best performing system after the $\mathrm{X}$ braced was the inverted V. In the upper stories 19th to 17 th, the reductions in displacements were higher in comparison to $\mathrm{X}$ braces. For the stories below these, $\mathrm{X}$ braces performed better. The differences between the two systems was marginal for most stories, with 
displacement differences being around 0.015-0.268 $\mathrm{mm}$ (the average difference was $0.0131 \mathrm{~mm}$ ).

In the case of the Combined braced frame, results did show a similar improvement in story drift as with the other systems. For the upper stories between 11-19, there was no improvement to the drift when compared to the $\mathrm{X}$ and inverted $\mathrm{V}$ systems. Conversely, lateral drift increased by an average of $0.046 \mathrm{~mm}$ between the 11th and 20th stories. However, for the lower stories between 110 , there was a minor improvement of an average of $0.008 \mathrm{~mm}$.

\subsection{Story acceleration}

Modal analysis results showed an increase in story accelerations as seen in Figs. 5 and 6. In the braced frames. In the $\mathrm{X}$ and $\mathrm{Y}$ directions, lateral accelerations increased in all stories, the increase ranging from $0.052 \%$ to $8.7 \%$ between the 1 st and 20th stories, with difference between the braced frames being significantly negligible. The increase was distributed unevenly throughout the frames. Large increases of were seen between the 20th $(6.1 \%)$ and 18th $(3.7 \%)$, and between the 12th (3.7\%) and 2nd (5.3\%) stories. The highest observed increase was the combined brace frame.

Significant rises in inter-story acceleration were observed in the $\mathrm{Z}$ direction for the braced frames.
This increase was indicative of lateral acceleration transfer in the frames. The increase, as seen in Fig. 7 varied in range for different story groups in the braced frames.

Between the 19th and 17th stories, the increase ranged between $85-60 \%$ respectively (with the highest from the combined braced frame and lowest from the V Braced frame). From the 16th to 10th stories, the range decreased by around 10\% (75$50.4 \%$ ). For the 9 th to 1 st story, similarly the decrease was by slightly above $10 \%$, However the range being $64-17 \%$. For these stories, the Combined brace (similar with the $\mathrm{X}$ braced frame) had the highest percentage range; 64-61.2\%, Inverted V 52.2-31\%, V 47.8-20.5\%.

As with the drift performance, the combined frame followed a similar pattern regarding story accelerations. Increases in accelerations followed a pattern similar to that of the $\mathrm{X}$ and Inverted $\mathrm{V}$ frames. For story ranges 20 to 11 (inverted V section), the acceleration increased by ranges of:2.32-2.88 mm/s $/ \mathrm{s}^{2}$ (X-direction), 2.92-4.37 mm/ $/ \mathrm{s}^{2}$ (Y-direction) and $0.54-1.94 \mathrm{~mm} / \mathrm{s}^{2}$ (Z-direction). For stories 10 to 1 (X braced section), there were variations (increases and decreases) in story accelerations in all three directions. In the $X$ direction, the variations ranged from -1.04 to 0.98 $\mathrm{mm} / \mathrm{s}^{2}$, Y was -1.45 to $-0.32 \mathrm{~mm} / \mathrm{s}^{2}$ and in the $\mathrm{Z}$ direction, the range was -0.11 to $0.19 \mathrm{~mm} / \mathrm{s}^{2}$.

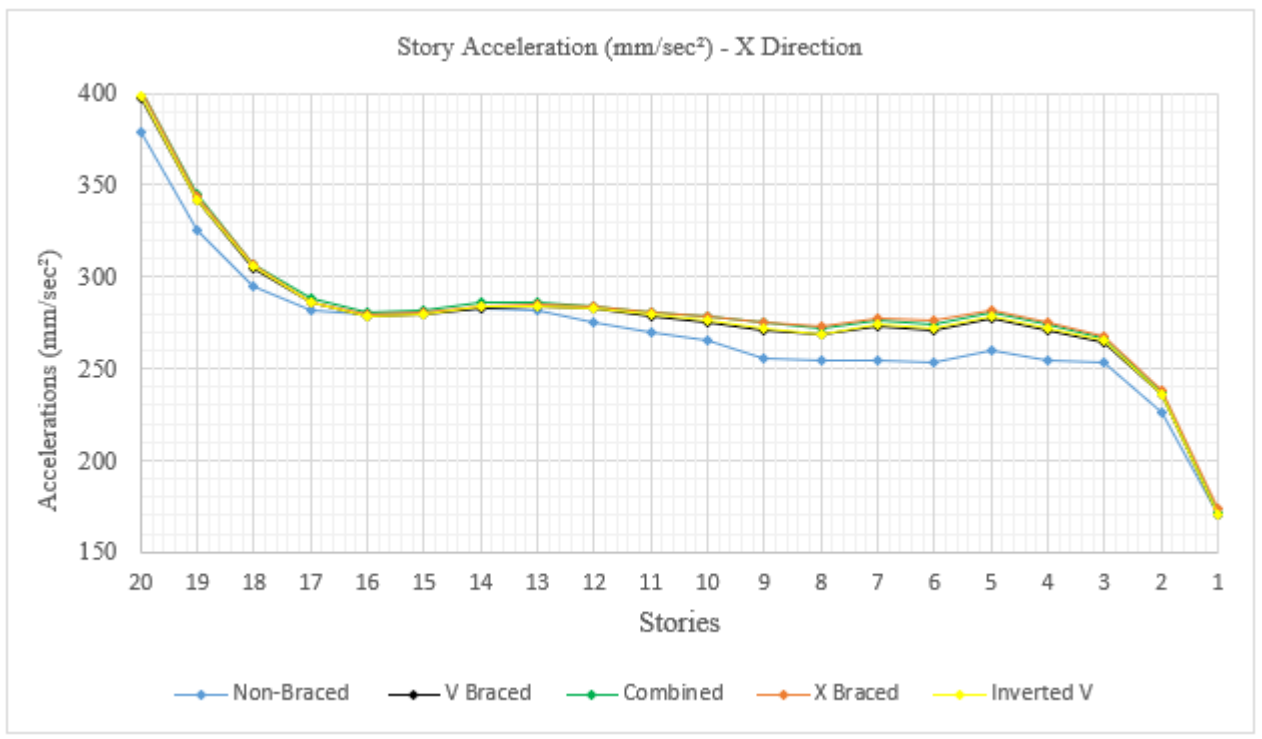

Fig. 5. Story acceleration $\left(\mathrm{mm} / \mathrm{s}^{2}\right)$ - X direction 


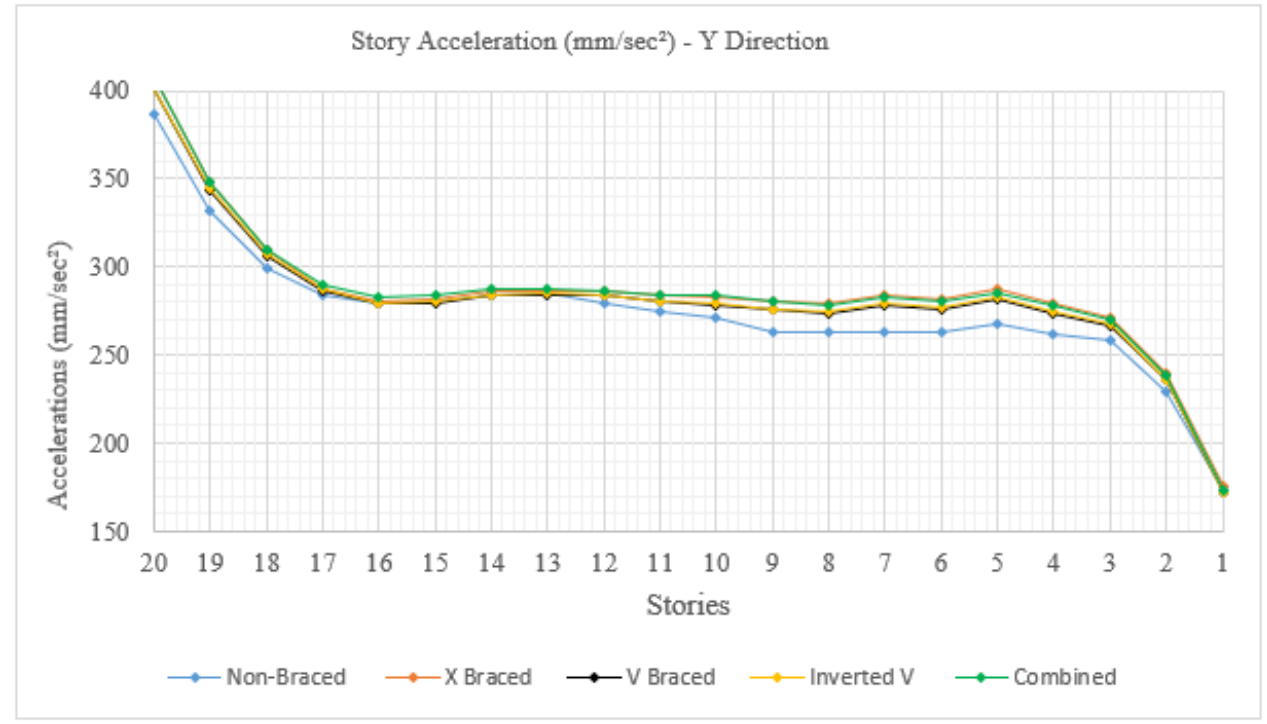

Fig. 6. Story acceleration $\left(\mathrm{mm} / \mathrm{s}^{2}\right)-\mathrm{Y}$ direction

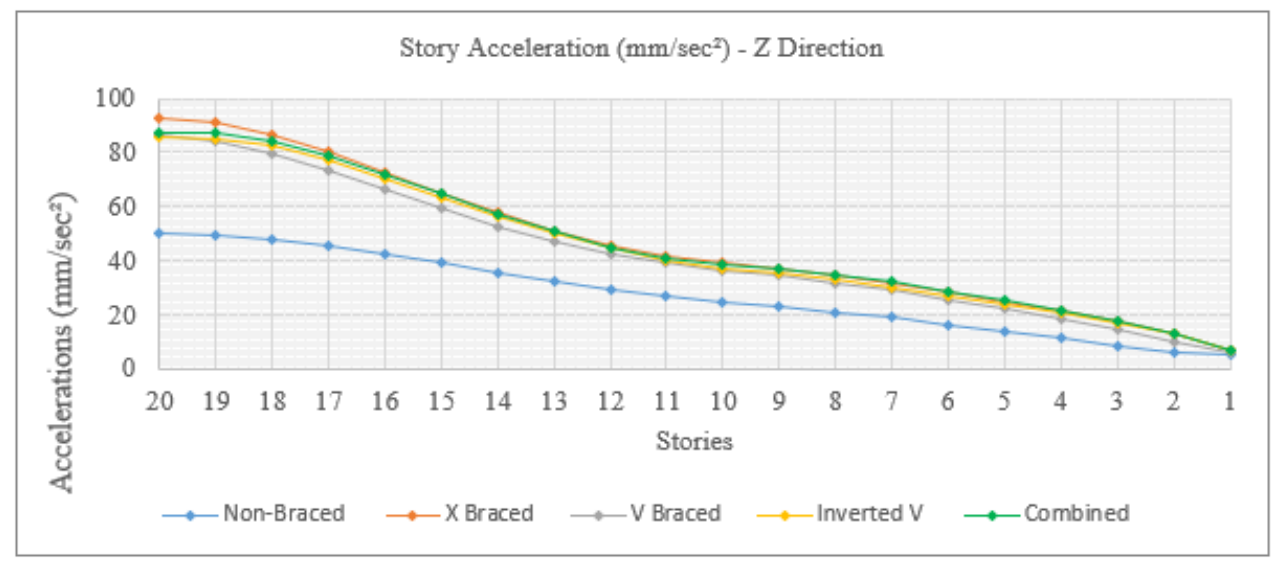

Fig. 7. Story accelerations of modelled frames in the $\mathrm{Z}$ direction

\subsection{Joint displacements}

Results indicated that displacements at joints for all stories followed an identical pattern to that of story drifts. With the braced frames, displacements decreased by frame type. The combined ( $\mathrm{X}$ and $\mathrm{V}$ ) braced frame recorded the best overall performance, with displacements reduced by a range of $21.7 \%$ (20th story lowest percentage) to $67.4 \%$ (1st story highest percentage).

Directionally, in the $\mathrm{X}$ and $\mathrm{Y}$ planes (Figs. 8 and 9), joint displacements decreased by a range of 21.7 to $67.4 \%$ (X-stories $20-1$ ) and $17.06 \%$ to $65.9 \%$ (Ystories 20-1). Comparatively, the $\mathrm{X}$ braced frame marginally performed better in the upper stories (between the 12th and 20th stories, and the 10th story), with displacement difference averaging $0.132 \mathrm{~mm}$.

However, in the $\mathrm{Z}$ direction (Fig. 10), displacements increased by a range of 5.6\% (20th story - lowest percentage) to $41.1 \%$ (4th story highest percentage) for the combined frame. It was only in the 1st story where the was a displacement reduction between the unbraced and combined frame $-5.6 \%(0.026 \mathrm{~mm})$. This increase in displacements was shared across all braced frames, with the difference between them ranging between 0.012 to $0.230 \mathrm{~mm}$. This increase can be attributed to joint acceleration increases in the $\mathrm{Z}$ direction. 


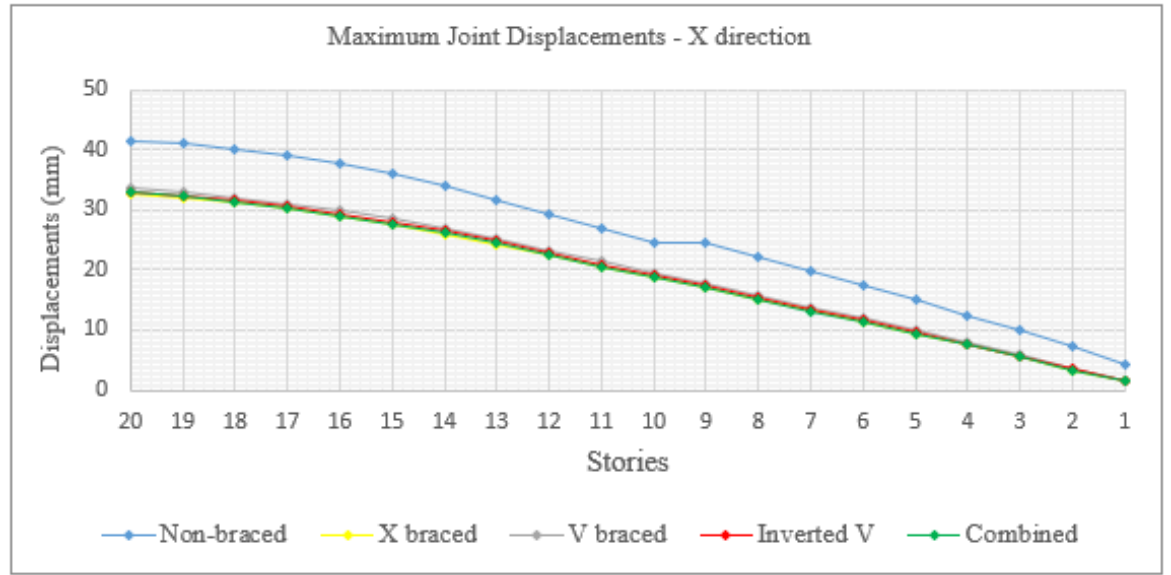

Fig. 8. Maximum joint displacement - $\mathrm{X}$ direction

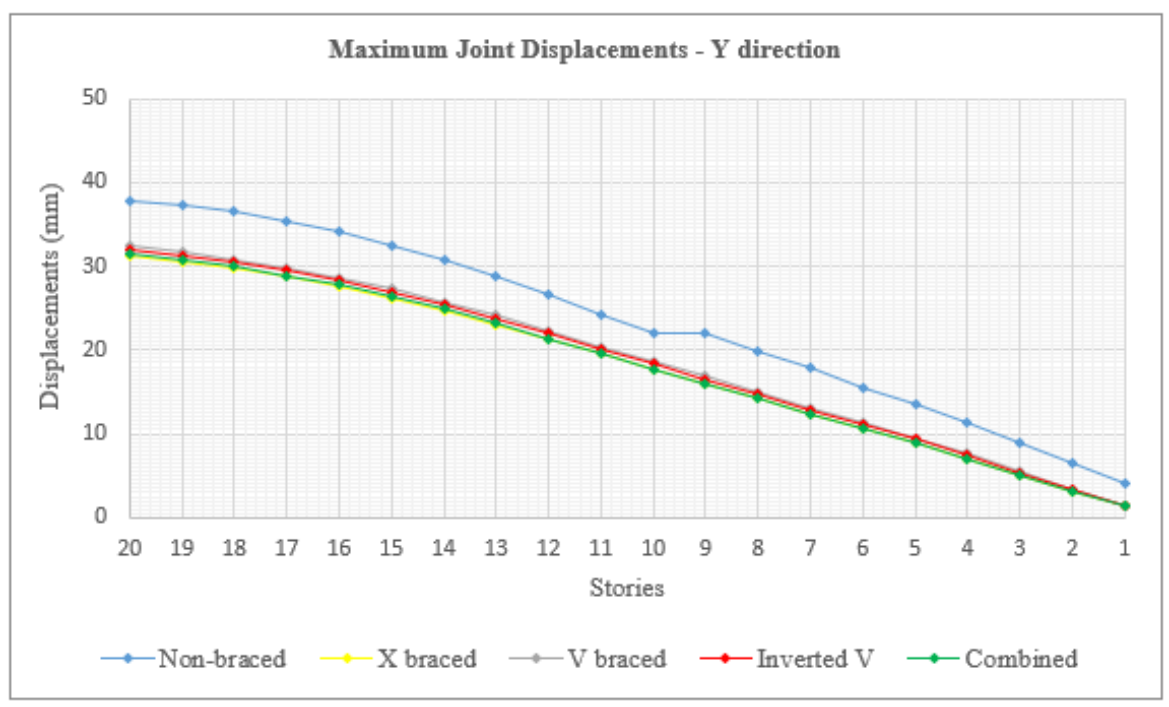

Fig. 9. Maximum joint displacements - Y direction

\subsection{Joint accelerations}

As with the story accelerations results, joint acceleration results followed a nearly identical pattern. There were increases in joint accelerations for all the braced frames in comparison to the Nonbraced frame. In the $\mathrm{X}$ and $\mathrm{Y}$ directions (Figs. 11 and 12), increases in lateral acceleration occurred for all braced frames between the 3rd and 20th stories. The $\mathrm{X}$ and combined frames recorded the largest increases in accelerations were in the 20th and lower stories between the 3rd and the 10th, where the increase was by around an average of 14 $\mathrm{mm} / \mathrm{s}^{2}$ while in other stories, the increases were less than $10 \mathrm{~mm} / \mathrm{s}^{2}$.
Significant acceleration increases were observed in the $\mathrm{Z}$ direction (Fig. 13). The increases were observed in the $\mathrm{X}$ braced frame, where; between the 20th and 15th stories $-83.6-66.9 \%$ respectively, 14 th and 2 nd stories $-62.9-49.5 \%$ and for the 1 st story $-20.4 \%$. The differences between the $\mathrm{X}$ and combined frame were small. Noticeable difference occurred only in the 20th story -4.99 $\mathrm{mm} / \mathrm{s}^{2}$, after this the differences in other stories were $1.5 \mathrm{~mm} / \mathrm{s}^{2}$ or considerably less.

\subsection{Structural stiffness}

From the modal analysis, it was observed that there was an increase in frame stiffness due to the incorporation of braces. 


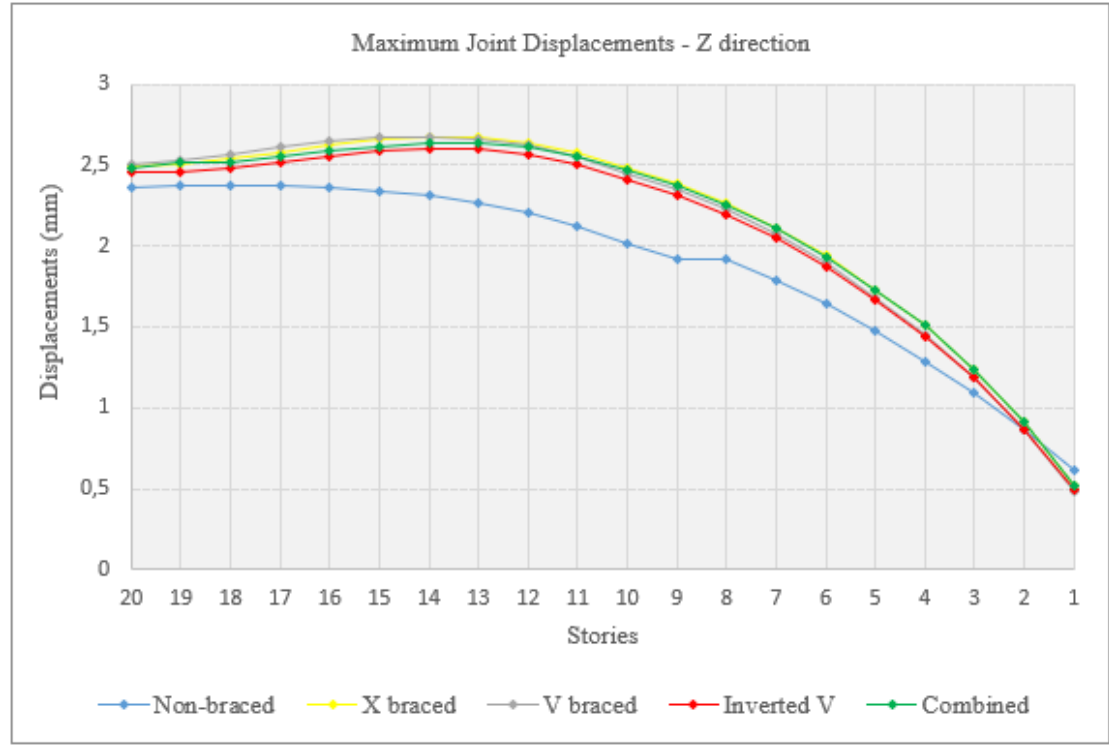

Fig. 10. Maximum joint displacements - $\mathrm{Z}$ direction

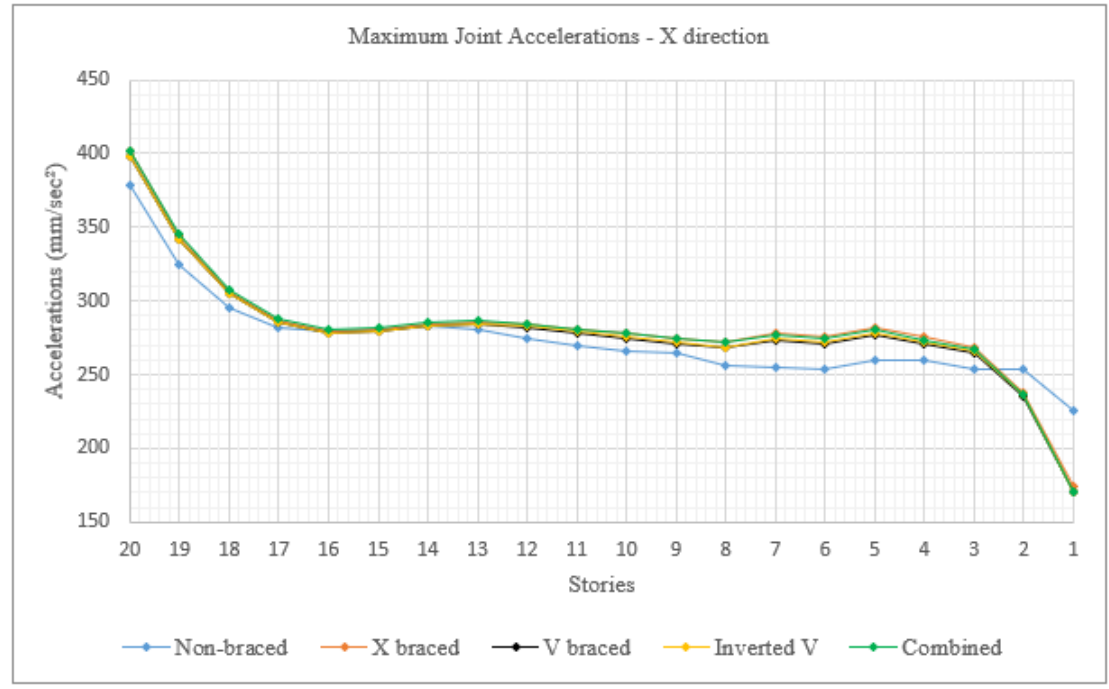

Fig. 11. Maximum joint accelerations - $\mathrm{X}$ direction

Substantial increases in stiffness occurred in both $\mathrm{X}$ and $\mathrm{Y}$ directions, excluding the 20th story, where there was a reduction (Figs. 14 and 15). Comparing the uniformly braced frames regarding stiffness, the best all round performance was observed in the $\mathrm{X}$ braced frame, where the increase ranged from $36.2 \%$ (3rd story) to $9.1 \%$ (19th story). For the other frames, their percentage ranges were: for Inverted V, 32.4\% (3rd story) to $11.4 \%$ (19th story), and for the $\mathrm{V}$ frame, $29.9 \%$ (3rd story) to $11.01 \%$ (19th story).

A similar pattern was observed in the $\mathrm{Y}$ direction, where the $\mathrm{X}$ braced frame performed better than the others, having a range of $30.3 \%$ (3rd story) to $7.01 \%$ (19th story), while for the inverted $\mathrm{V}-24.1 \%$ (3rd story) to $8.6 \%$ (19th story) and for the $\mathrm{V}$ frame $-22.1 \%$ (3rd story) to $6.6 \%$ (19th story). 


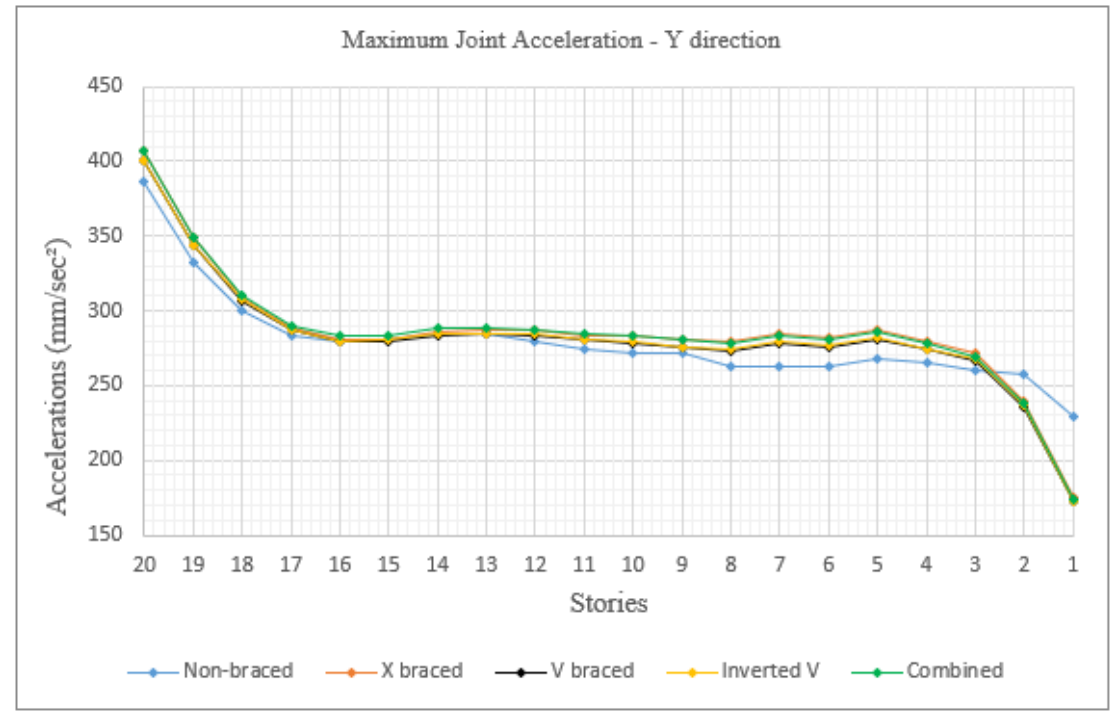

Fig.12. Maximum joint acceleration - Y direction

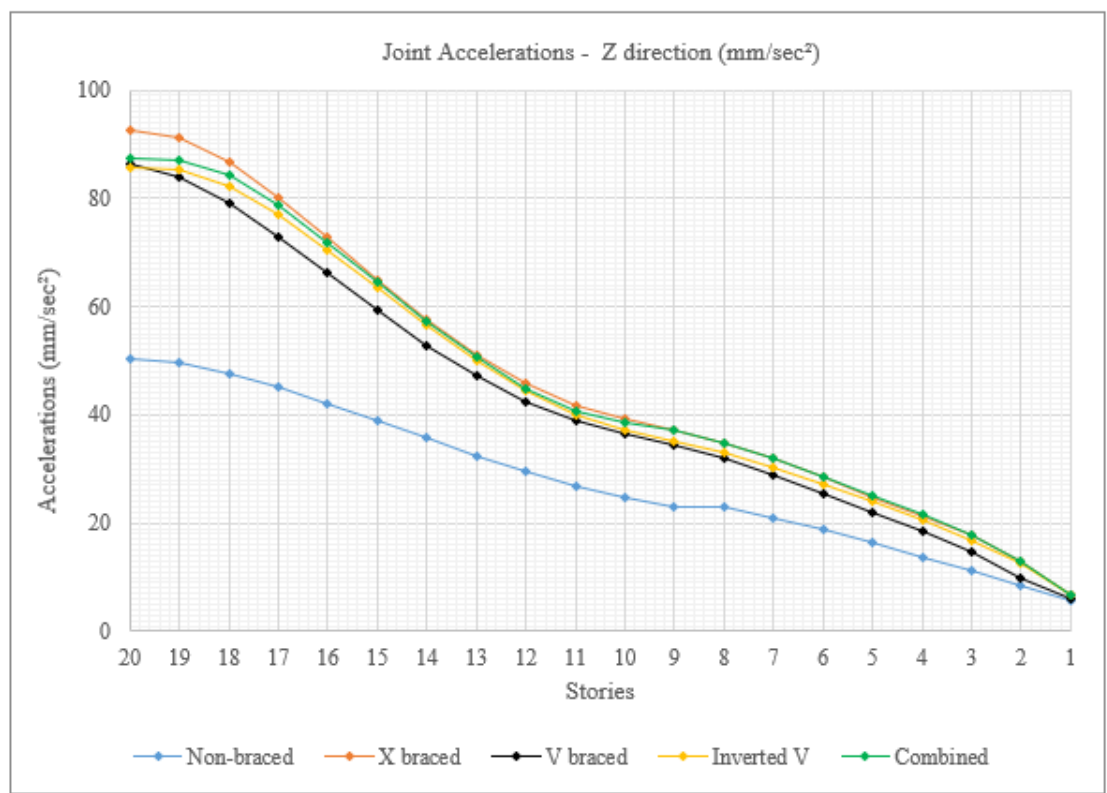

Fig. 13. Maximum joint accelerations - $\mathrm{Z}$ direction

In the case of combined frame, the stiffness improvement was similar to that of the uniform systems. Comparatively, the combined frame did not perform better than the $\mathrm{X}$ and inverted $\mathrm{V}$ frames in the upper stories (11-19) with difference between them being considerable. In the lower stories (1$10)$, there was a small marginal increase of around $0.4-1 \%$.

From the plot data presented in Figs 6 and 7, it can be observed that behaviourally, the increase in stiffness in the braced frames pattern similar to that of non-braced frame.

\subsection{Base reactions}

From Table 3, it can be observed that there were small increases in the base shear of the braced frames. The highest increase was in the $\mathrm{X}$ braced frame $-2.34 \%$ and $1.66 \%$ (FX and FY respectively) and $2.07 \%$ and $1,67 \%$ in the combined frame. 


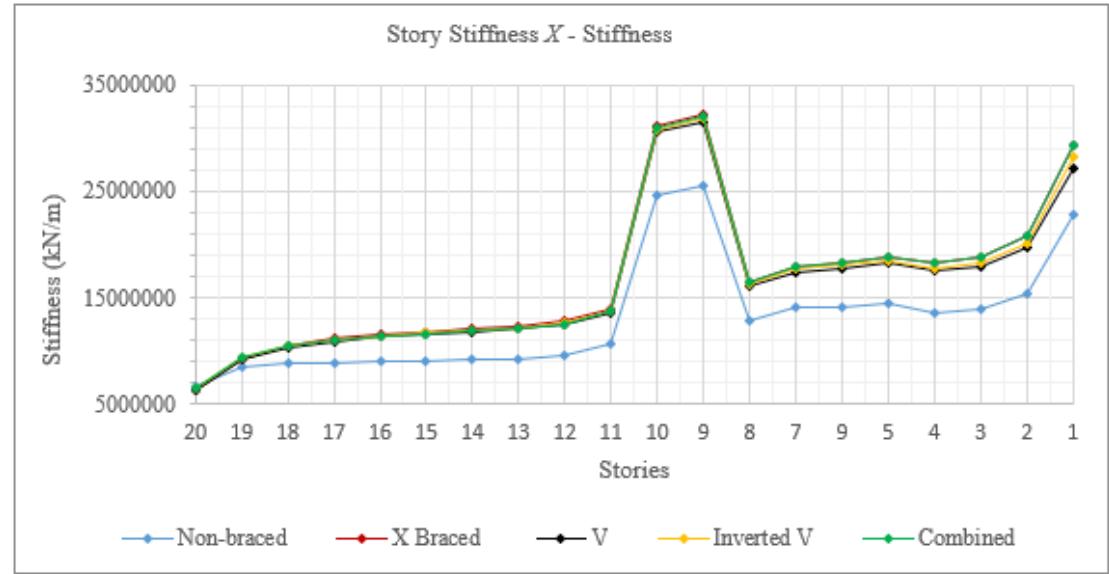

Fig. 14. Story stiffness - X direction

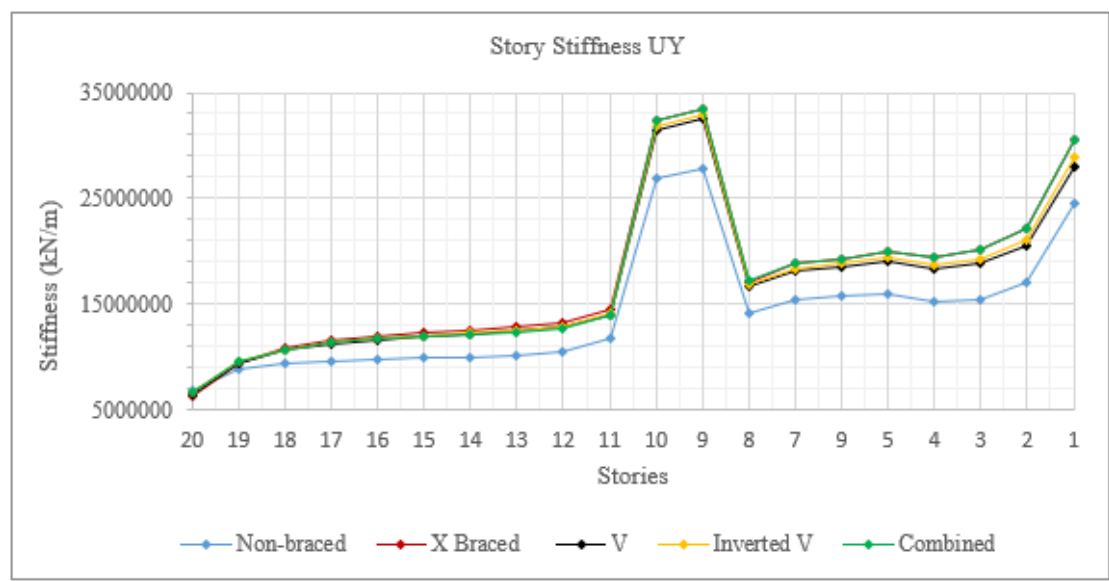

Fig. 15. Story stiffness - Y Direction

Table 3. Base reactions for all frames

\begin{tabular}{lcccccc}
\hline \multirow{2}{*}{ Frame type } & \multicolumn{3}{c}{ Base shear $(\mathrm{kN})$} & \multicolumn{3}{c}{ Base moments $(\mathrm{kN}-\mathrm{m})$} \\
\cline { 2 - 7 } & FX & FY & FZ & MX & MY & MZ \\
\hline Non-Braced & 38965.226 & 39192.415 & 0 & 1735406.1 & 1737487.5 & 1762296.5 \\
X braced & 39889.391 & 39991.075 & 0 & 1741299.4 & 1744418.8 & 1800520.9 \\
V braced & 39780.75 & 39855.286 & 0 & 1742582.7 & 1744295.2 & 1794893.6 \\
Inverted V braced & 39782.755 & 39856.855 & 0 & 1741192.3 & 1742951.5 & 1794976.9 \\
Combined & 39791.173 & 39859.715 & 0 & 1735407.3 & 1739582.8 & 1795235.9 \\
\hline
\end{tabular}

For the base moments, the increase varied with frame types, MX - $0.43 \%$ (V braced), MY $-0.40 \%$ (X braced) and MZ - 2.12\% (X braced). For all the braced frames, both shear and moment forces increased by small margins as stated and thus showed no improvement to frames' base reactions. 


\subsection{Discussion of results}

From the results, a general observation can be made that the incorporation braces into RC frame has made a noticeable improvement in the seismic performance. Improvements in story drift show that the braced frames have been able to improve the torsional performance of the frames. Additionally, stiffening the frames with braces also had an effect on joint displacements and accelerations.

\subsubsection{Story drift and effect of stiffness}

From the modelling analysis, the frames' lateral drift limit was determined to be $52.5 \mathrm{~mm}$ (Nonbraced frame story drift average) of each isolated story. In this case, all the frames passed this criterion; maximum recorded displacement in the $\mathrm{X}$ direction being: $2.84 \mathrm{~mm}$ (Non-braced), $2.106 \mathrm{~mm}$ (Combined), $2.11 \mathrm{~mm}$ (X braced), $2.217 \mathrm{~mm}$ (V braced) and $2.17 \mathrm{~mm}$ (Inverted V) - all occurring in the 3rd story. The significant reduction indicates a substantial improvement in the torsional performance of the braced frames when compared to the non-braced.

A correlation can be made between the reduction of story drift with the increase in story stiffness. This is done by comparing the ratios of story drift performance - Drift Braced / Drift Nonbraced and that of Stiffness - Stiffness Braced / Stiffness Non-braced. In Figs. 16 and 17, the relationship between increase in story stiffness and decrease in lateral drift can be seen. In the comparison, the braced frames had similar correlation coefficients, where in the $\mathrm{X}$ direction, it was 0.982 ( $\mathrm{X}$ and Combined braced), 0.981 (Inverted V braced), and 0.980 (V braced). As for the $\mathrm{Y}$ direction, it was 0.982 (V braced), 0.980 (X and Inverted $\mathrm{V}$ braced) and 0.977 (Combined braced).

\subsubsection{Effect of story stiffness on joint} displacements and accelerations

Overall increases in story and joint acceleration for the braced frames show an improvement in the energy transfer, distribution and absorption in the braced frames. Comparatively, the best performing frames were the $\mathrm{X}$ and combined.

The acceleration and drift performance of the braced frames in comparison to that of the unbraced frame, can be attributed to the increased story stiffness of the frame. The relationship between joint displacement and story stiffness can be observed by comparing the ratios of story joint displacement (Displacement Braced / Displacement Non-braced) and story stiffness (Stiffness Braced / Stiffness Non-braced in the $\mathrm{X}$ and $\mathrm{Y}$ directions, it can be seen in the plots data from Figs. 18 and 19. Though not identical to that of story drift and stiffness, there is a correlative behaviour that is seen in the reduction of displacements with the increase of story stiffness.

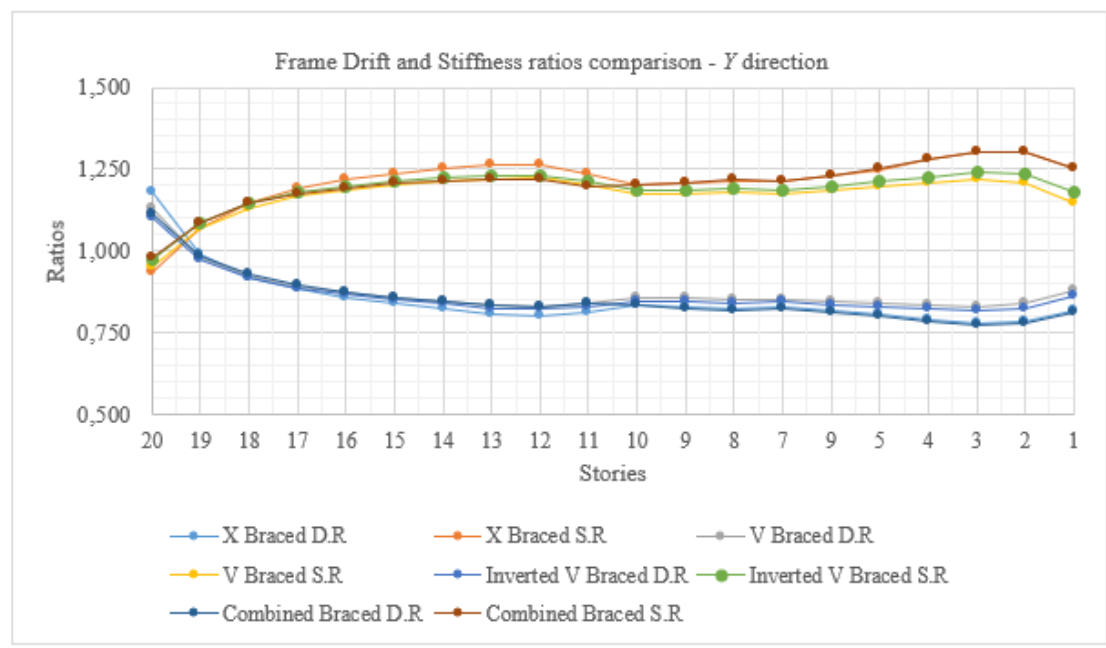

Fig. 16. Plot data for $Y$ direction story drift and stiffness ratios 


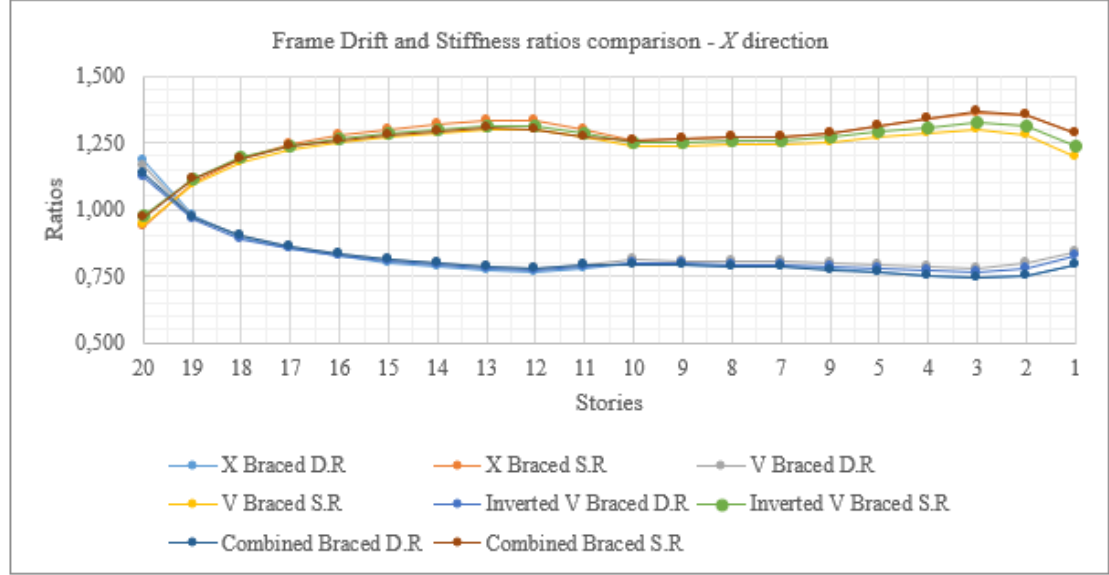

Fig. 17. Plot data for $X$ direction story drift and stiffness ratios

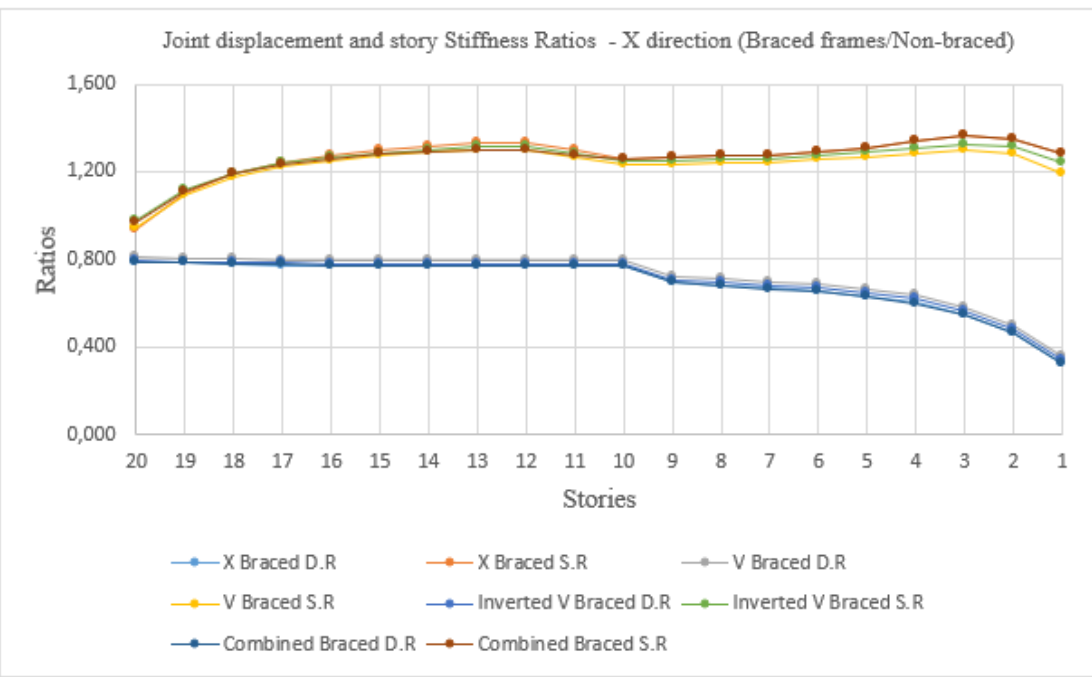

Fig. 18. Joint displacement and story stiffness ratios - X direction (Braced frames/Non-braced)

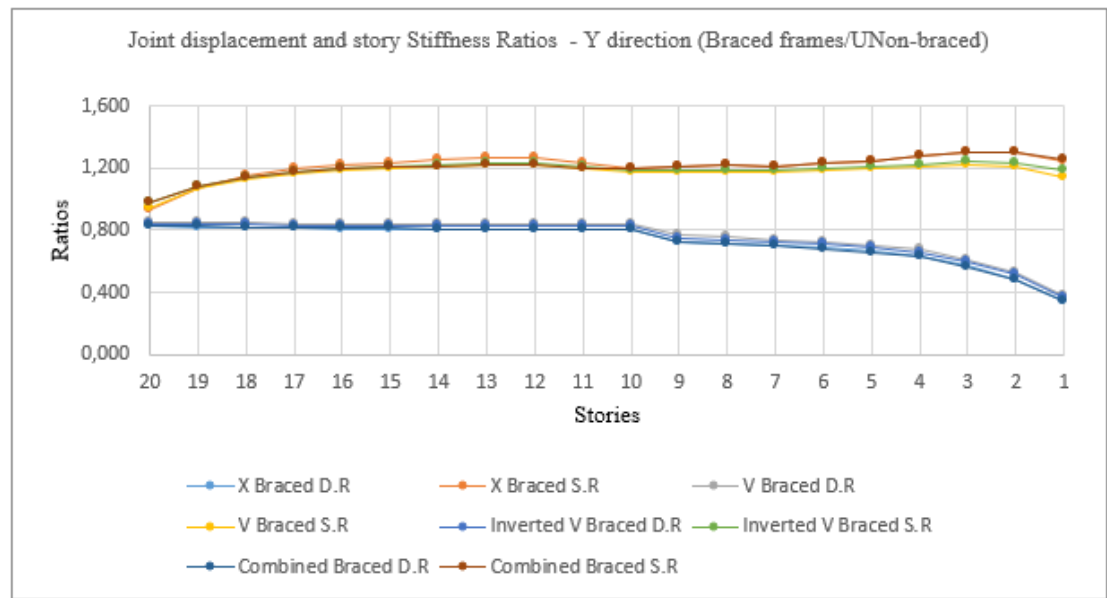

Fig. 19. Joint displacement and story stiffness ratios - X direction (Braced frames/Non-braced) 
Comparing the braced frames, the highest coefficient was found in the Combined: -0.464 (X) and $-0.602(\mathrm{Y})$, both directions showing an inverse relationship. This relationship was also found in the other frames, although their coefficients were significantly lower in comparison, with their values being the $\mathrm{X}$ braced: $-0.38(\mathrm{X})$ and $-0.446(\mathrm{Y})$, Inverted V: $-0.266(\mathrm{X})$ and $-0.278(\mathrm{Y})$, and $\mathrm{V}$ braced: $-0.183(\mathrm{X})$ and $-0.178(\mathrm{Y})$.

The observed increase of accelerations in the $\mathrm{Z}$ direction in the joints and subsequent increase in displacements, showed that the braces were able to transfer lateral accelerations from the $\mathrm{X}$ and $\mathrm{Y}$ planes to the $\mathrm{Z}$ frame, indicating the braces were able to distribute and absorb lateral forces throughout the frames better than the unbraced frame. A positive correlation can be observed when comparing the ratios of increased joint displacement (Displacement braced / displacement Non-braced) and joint accelerations (Acceleration braced / Acceleration Non-braced). These ratios can be seen in the plot data presented in Fig. 20. The highest correlation or whole structure was observed in the $\mathrm{V}$ braced frame with 0.430 . As for the others, their values were considerably low in comparison. The Inverted V was 0.251, the Combined braced 0.209 and the $\mathrm{X}$ frame was 0.145 .

The highest correlative behaviour was seen between the 20th and 10th stories of the braced frames where they followed a near direct relationship; having a coefficient average of 0.97
(X braced: 0.96, V braced: 0.96, Inverted V braced: 0.98 and Combined braced: 0.95). From the 9th to 3rd stories, there was great variation in the braced frames when compared. The highest was seen in the $\mathrm{V}$ braced frame with 0.97 , followed by the combined frame with $0.53, \mathrm{X}$ braced frame with 0.45 and lowest being the inverted $\mathrm{V}$ with 0.20 .

\section{Conclusions}

From the results of the modelling of these frames, following guideline set by Eurocode for capacity and seismic assessment, there are several performance improvements that are offered with the incorporation of concentric braces - uniform or combined. The following conclusions can be derived from the MRSA:

1. There is a substantial increase in frame stiffness with use of braces. As was seen, structural stiffness of the braced frames was increased from the top stories to bottom stories. The observed improvements in drift and accelerations can be attributed to the stiffness increase.

2. The lateral drifts of both story and frame undergo significant reductions with the use of braces, and based on these observations that the best concentric system to employ would be the $\mathrm{X}$ braced system that had the best overall performance.

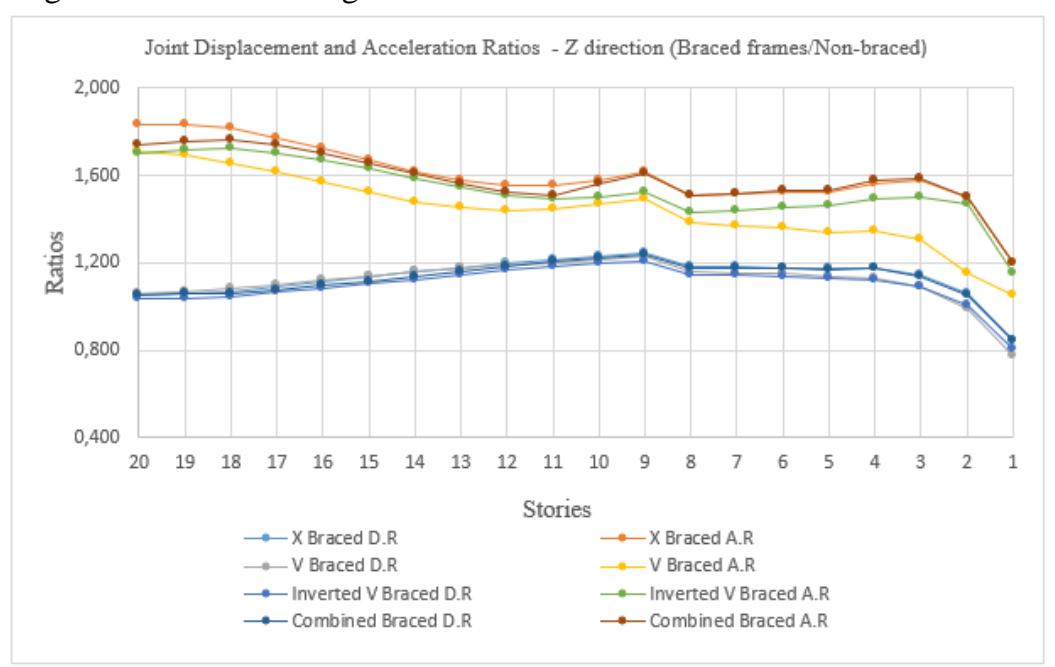

Fig. 20. Joint displacement and acceleration ratios - Z direction (Braced frames/Non-braced 
There are increases in lateral accelerations for stories and joints from the ground to the upper stories indicating a large and more even transfer of lateral accelerations from the base to the top of a frame with the use of braces. Additionally, there was a high correlation linking stiffening to reduction in story drift in both $\mathrm{X}$ and $\mathrm{Y}$ directions - an average of 0.98 for both directions.

3. The increase in story and joint accelerations in the upper stories indicated an improvement in a frames' ability to absorb and distribute seismic energy. This is especially in case of the $\mathrm{Z}$ plane (perpendicular to the lateral load), where the largest accelerations and decreased displacements were recorded in stories above the 5th story of each braced frames. Another notable point regarding the transfer of lateral accelerations in the $\mathrm{Z}$ direction is that there is somewhat predictable behaviour observed when observing the relationship between joint displacements and accelerations; this especially in the case of the stories above the 10th story of the braced frames.

4. In comparing bracing systems, it was can be seen that there some performance improvements when combined. These improvements are however, marginal when factoring in the frames' global performance.

5. Base reaction results showed that there was rather low increase shear and moments with the incorporation of braces. The improvement was small - less than a $3 \%$ increase in base forces.

\section{Declaration of conflicting interests}

The author(s) declared no potential conflicts of interest with respect to the research, authorship, and/or publication of this article.

\section{References}

[1] Godínez-Domínguez EA, Tena-Colunga A (2010) Nonlinear behaviour of code-designed reinforced concrete concentric braced frames under lateral loading. Engineering Structures 32:944-963.
[2] Maheri MR (1997) Use of steel bracing in reinforced concrete frames. Engineering Structures 19(12):1018-1024.

[3] Bush TD, Jones EA, and Jirsa JO (1991) Behavior of RC frame strengthened using structural steel bracing. Journal of Structural Engineering 117(4):1115-1126.

[4] Higashi Y, Endo T, and Shimizu Y. Experimental studies on retrofitting of reinforced concrete structural members. Proceedings of 2nd Seminar on Repair and Retrofit of Structures. National Science Foundation, Ann Arbour, Michigan, pp. 126-155, 1981.

[5] Badoux M, and Jirsa JO (1990) Steel bracing of RC frames for seismic retrofitting. Journal of Structural Engineering 116(1):55-74.

[6] Maheri M R, and Akbari R (2003) Seismic behaviour factor, $\mathrm{R}$, for steel $\mathrm{X}$-braced and kneebraced RC buildings. Engineering Structures 25:1505-1513

[7] Youssef MA, Ghaffarzadeh H, Nehdi M (2007) Seismic performance of RC frames with concentric internal steel bracing. Engineering Structures 29:1561-1568

[8] Godínez-Domínguez EA, Tena-Colunga A, PérezRocha LE (2012) Case studies on the seismic behavior of reinforced concrete chevron braced framed buildings. Engineering Structures 25:78103

[9] Zhe Q, Shoichi K, Yusuke M, Hiroyasu S, Akira Q (2015) Seismic responses of reinforced concrete frames with buckling restrained braces in zigzag configuration. Engineering Structures 105:12-21

[10] Roudsari MT, Entezari A, Hadidi. MH (2017) Experimental assessment of retrofitted rc frames with different steel braces. Structures 10(11):206217.

[11] Valente M (2013) Seismic protection of RC structures by a new dissipative bracing system. Procedia Engineering 54:785-794.

[12] Tsionis G, Apostolsk R, Taucer. F (2014) Seismic strengthening of RC structures: Literature review.: Institute for the Protection and Security of the Citizen. Report No: 1831-9424, Luxembourg.

[13] Maheri M R (2005) Recent advances in seismic retrofit of RC frames. Asian Journal of Civil Engineering 6(5):373-391.

[14] Muralidhar GB, Swathi RKS (2016) Comparison of performance of lateral load resisting systems in multi storey flat slab building. International Journal 
of Research in Engineering and Technology 5(3):15-19.

[15] Vijayakumar M, Manivel S, Arokiaprakash A (2016) Study on seismic performance of rcc frame with various bracing systems using base isolation technique. International Journal of Applied Engineering Research 11(10):7030-7033.
[16] Fardis MN. Seismic Design, assessment and retrofitting of concrete buildings based on ENEurocode8. Springer Dordrecht Heidelberg, London/New York, 2009. 